\title{
Makna Idola Dalam Pandangan Penggemar (Studi Komparasi Interaksi Parasosial Fanboy dan Fangirl ARMY Terhadap BTS)
}

\author{
Jeanette, Sinta Paramita \\ jeanette.915150144@stu.untar.ac.id
}

Fakultas Ilmu Komunikasi Universitas Tarumanagara

\begin{abstract}
Supported by globalization and advancement in information technology, popular culture can easily accessed, especially K-Pop. BTS is one of the most successful K-Pop artists and has many fans from all over the world including Indonesia. The presence of idols like BTS indirectly makes fans form parasocial interaction. Parasocial interaction is a relationship of attachment that is intertwined with figures that appear in the media. This study discusses the difference in parasocial interaction between fangirl and fanboy ARMY towards BTS. This study used a qualitative approach with a case study research strategy. The subjects in this study is six ARMY, three women (fangirl) and three men (fanboy). The conclusions in this study indicate that fangirl like BTS emotionally (best friend, brother and romantic relationship), while fanboy like BTS rationally (idol, role model and music quality). Fangirl is more active in community activities, on the other hand fanboy is not interest to be a community member and support BTS in certain limitations.
\end{abstract}

Keywords: BTS, ARMY, Parasosical Interaction, K-Pop, Comparative Study

\begin{abstract}
Abstrak
Didukung dengan globalisasi dan perkembangan teknologi informasi, budaya popular bisa dengan mudah diakses, terutama K-Pop. BTS merupakan salah satu artis K-Pop paling sukses dan memiliki banyak penggemar di seluruh dunia termasuk Indonesia. Kehadiran idola seperti BTS secara tidak langsung membuat penggemar membentuk interaksi paarasosial. Interaksi parasosial adalah hubungan kelekatan yang terjalin dengan tokoh yang muncul di media. Penelitian ini membahas perbedaan interaksi parasosial antara penggemar perempuan dan laki-laki terhadap BTS. Penelitian ini menggunakan pendekatan kualitatif dengan strategi penelitian studi kasus. Subjek penelitian berjumlah enam orang ARMY, tiga orang perempuan (fangirl) dan tiga orang laki-laki (fanboy). Kesimpulan dalam penelitian ini menunjukkan bahwa penggemar perempuan menyukai BTS secara emosional (sahabat, saudara dan hubungan romantis), sedangkan penggemar laki-laki menyukai BTS secara rasional (idola, panutan dan kualitas musik). Penggemar perempuan lebih aktif dalam aktivitas komunitas, di sisi lain penggemar laki-laki tidak tertarik untuk menjadi anggota komunitas dan mendukung BTS dengan batasan-batasan tertentu.
\end{abstract}

Kata kunci: BTS, ARMY, Interaksi Parasosial, K-Pop, Studi Komparasi

\section{Pendahuluan}

Di zaman sekarang yang sangat maju, kehadiran teknologi memberikan pengaruh yang sangat besar dalam kehidupan manusia. Kemajuan teknologi di era 
globalisasi membuka jendela penyebaran informasi dan menjadi faktor yang dominan dalam arus informasi. Salah satu pengaruh dari kemajuan terknologi adalah penggunaan media online. Dengan bantuan media online, semua dapat diakses tanpa batas jarak dan waktu. Hal ini mempermudah pertukaran informasi bahkan budaya antar negara.

Fenomena di dalam dunia hiburan saat ini sangat menarik perhatian. Setelah masyarakat mulai bosan dengan budaya popular Amerika, muncullah budaya alternatif dari Korea Selatan. Budaya popular Korea mulai menguasai segala aspek kehidupan di wilayah Asia bahkan mulai merambah ke Eropa dan Amerika. K-Pop merupakan singkatan dari Korean Pop atau Korean Popular Music adalah sebuah genre musik yang berasal dari Korea Selatan. Penampil K-Pop tidak hanya memanjakan telinga tetapi juga memanjakan mata dengan tampilan yang rupawan dan pertunjukan panggung yang sudah sangat terlatih.

Dalam perkembangannya, K-Pop tumbuh menjadi sebuah subkultur yang menyebar secara luas di berbagai belahan dunia. Sampai saat ini banyak artis K-Pop yang berhasil menembus batas dalam negeri dan populer di mancanegara seperti Super Junior, SHINee, BIGBANG, Wanna One, TWICE, EXO, GOT7, iKON, BLACKPINK, Stray Kids, 2NE1, Girls' Generation, dan BTS.

Budaya itu akan memperoleh kekuatannya manakala media massa digunakan sebagai penyebaran pengaruh di masyarakat (Bungin, 2009:100). Hasil dari gelombang penyebaran budaya Korea bentuk baru ini melahirkan banyak grup idola yang mulai populer secara global. Dari sekian banyak grup idola dengan kepopuleran tinggi baik dunia nyata maupun dunia maya, boy group BTS menjadi sorotan penulis.

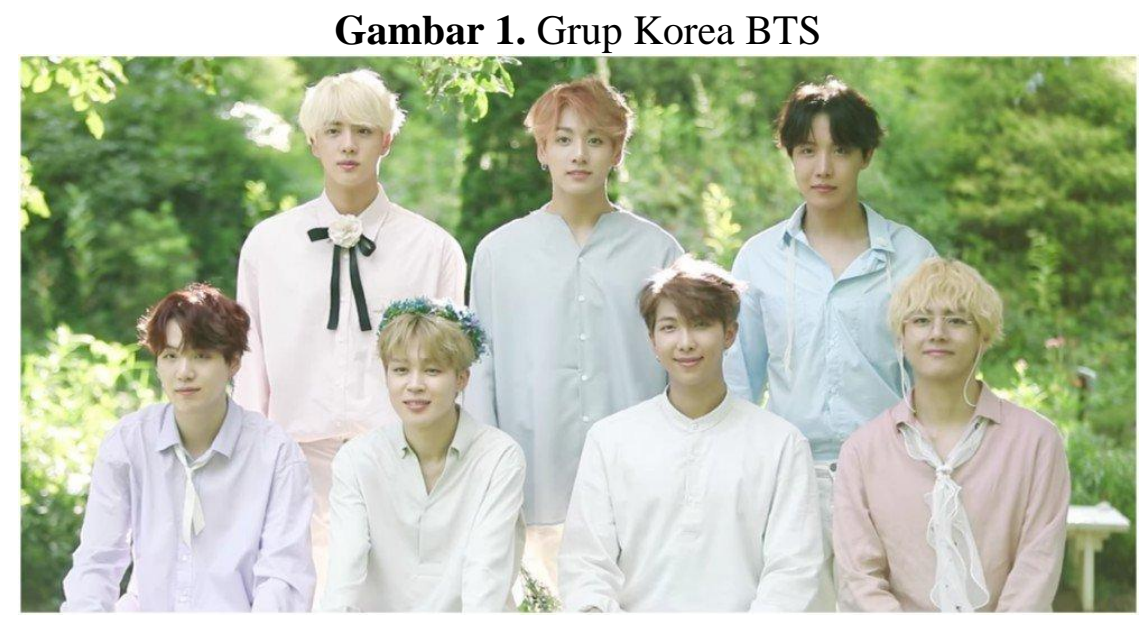

Sumber: www.allkpop.com

BTS atau Bangtan Boys (방탄소년단) adalah boy band asal Korea Selatan bentukan Big Hit Entertaiment yang beranggotakan tujuh orang, yakni RM, Jin, Suga, J-Hope, Jimin, V, dan Jungkook. Grup ini diperkenalkan ke publik tahun 2013. Saat ini BTS mendapatkan predikat sebagai boy band K-Pop terbesar karena tidak hanya berjaya di industri hiburan Korea Selatan saja, mereka sudah dikenal secara global dengan popularitas yang mendunia.

Pada tahun 2018, BTS menduduki peringkat kelima dalam daftar Korea Power Celebrity dalam majalah Forbes. BTS juga berhasil menjadi penerima termuda penghargaan pemerintahan Korea Selatan "Order of Cultural Merit". Pada bulan September 2018, BTS mendapatkan kesempatan memberikan pidato di United Nations 
sebagai perwakilan dari UNICEF. Pada Oktober 2018, BTS terpilih untuk mengisi halaman utama majalah 'Time' dan diberi julukan 'Next Generation Leaders'.

Sampai saat ini BTS terus mencatat sejarah dan pencapaian yang banyak dan besar. BTS bahkan mampu melakukan kolaborasi dengan artis papan atas seperti The Chainsmokers, Steve Aoki dan Nicki Minaj. Kesuksesan yang diraih oleh BTS tidak lepas dari dukungan penggemarnya dari seluruh penjuru dunia.

Penggemar adalah seseorang yang menggemari sesuatu dengan antusias dan secara kolektif kelompok penggemar akan membentuk kelompok penggemar (fanbase) atau fandom. Fandom digunakan oleh penggemar untuk mencari informasi tentang idola mereka dan juga menjadi tempat berkomunikasi dengan kelompok dengan minat yang sama.

Di dalam fandom K-Pop, penggemar dikenal dengan dua sebutan berdasarkan jenis kelaminnya yaitu fangirl dan fanboy. Fangirl merupakan sebutan untuk penggemar perempuan dan fanboy merupakan sebutan untuk penggemar laki-laki. Biasanya fanboy akan lebih reaktif terhadap idola perempuan dan sebaliknya fangirl akan lebih reaktif saat melihat idola laki-laki.

Penggemar K-Pop dikenal dengan tingkat loyalitas yang sangat tinggi. Bentuk loyalitas yang ditunjukkan bukan hanya secara ekonomi tetapi juga waktu dan perbuatan. Penggemar K-Pop rela menghabiskan berjam-jam untuk melihat kegiatan idolanya. Penggemar K-Pop juga rela menghabiskan banyak uang bahkan mengorbankan kebutuhan pribadinya untuk membeli segala sesuatu yang berhubungan dengan idolanya.

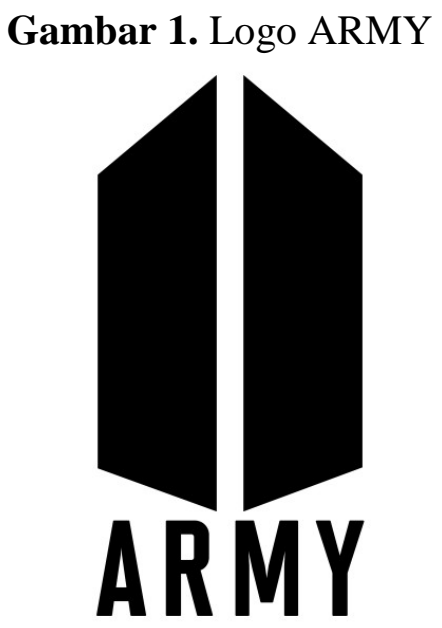

Sumber: Akun Resmi BTS

ARMY (Adorable Representative MC For Youth) adalah nama fandom pendukung BTS yang diumumkan pada tahun 2013. ARMY sebagai fandom resmi BTS merupakan fandom yang sangat aktif dalam dunia maya dan nyata. Mereka bahkan memenangkan beberapa penghargaan, salah satunya adalah 'Fandom Choice' di Teen Choice Awards 2018 mengalahkan penggemar artis internasional besar seperti Taylor Swift, Fifth Harmony, One Direction, dan CNCO.

Hubungan antara BTS dan ARMY dikenal sangat dekat dan berbeda dengan hubungan idola dan penggemar grup lain. BTS memperlakukan penggemarnya dengan sangat spesial dan selalu berusaha menciptakan hubungan yang dekat melalui media sosial. BTS bahkan menerima banyak sanjungan atas keaktifan mereka di media sosial dan dinobatkan oleh Forbes sebagai artis dengan jumlah retweet terbanyak di Twitter 
pada bulan Maret 2016. BTS bahkan menciptakan beberapa lagu yang didedikasikan khusus untuk ARMY seperti Spring Day, 2!3! dan Magic Shop.

ARMY juga dikenal sebagai fandom yang sangat aktif di media sosial. Salah satu hasil kegiatan media sosial yang dilakukan ARMY adalah ketika BTS masuk nominasi Top Social Media Artist dalam BBMAs 2017, para A.R.M.Y mendukung mereka dan berhasil mengumpulkan lebih dari 213 juta tweets. MV "Idol" milik BTS bahkan mengalahkan rekor yang dipegang oleh Taylor Swift karena berhasil mencapai 45 juta panayangan di Youtube hanya dalam waktu 24 jam sejak perilisannya.

Dedikasi seperti itu memicu timbulnya perasaan intim yang salah antara individu atau kelompok. Perasaan ini disebut sebagai "interaksi parasosial", interaksi yang terjadi ketika individu berinteraksi dengan orang yang dipresentasikan oleh media (mediated person) seolah-olah orang itu nyata (Setyanto, Winduwati dan Utami, 2017). Interaksi parasosial yang dialami oleh fangirl dan fanboy terhadap idolanya sangatlah berbeda. Hal itulah yang membuat peneliti tertarik untuk melihat bagaimana perbedaan interaksi parasosial yang dialami oleh fangirl dan fanboy boy group BTS.

\section{Metode Penelitian}

Metode penelitian yang digunakan dalam penelitian ini adalah kualitatif. Penelitian kualitatif merupakan proses untuk memahami masalah melalui penggambaran holistik atas masalah tersebut yang dibentuk dengan kata-kata, melaporkan dengan terperinci sesuai sudut pandang informan, dan disusun dalam latar ilmiah (Tamburian, 2018). Penelitian kualitatif dapat menunjukkan kehidupan masyarakat, sejarah, tingkah laku, fungsionalisasi organisasi, pergerakan sosial, dan hubungan kekerabatan. Di sini yang lebih ditekankan adalah persoalan kedalaman (kualitas) data, bukan banyaknya (kuantitas) data (Kriyantono, 2012).

Penelitian ini menggunakan strategi penelitian studi kasus. Yunus (2010) menggambarkan objek yang diteliti dalam penelitian studi kasus hanya mencitrakan dirinya sendiri secara mendalam/detail/lengkap untuk memperoleh gambaran yang utuh dari objek (wholeness) dalam artian bahwa data yang dikumpulkan dalam studi dipelajari sebagai suatu keseluruhan, utuh yang terintegrasi. Pendekatan studi kasus di peneletian ini akan mempelajari secara mendalam tentang interaksi parasosial fangirl dan fanboy dan mempelajari efek dari interaksi tersebut.

Berdasarkan sumbernya (Sugiyono,2009), data dibedakan menjadi dua yaitu data primer (dibuat oleh peneliti) dan data sekunder (data yang sudah terkumpulkan). Dalam penelitian ini menggunakan data primer yang dikumpulkan sendiri oleh peneliti dari narasumber dan observasi. Dalam penelitian ini juga menggunakan sumber data sekunder seperti buku, artikel, jurnal dan situs di internet yang berkaitan dengan penelitian yang dilakukan.

Metode pengumpulan data yang digunakan dalam penelitian ini adalah wawancara mendalam (in-depth Interview) sebagai pengumpulan data primernya. Peneliti bertujuan menggali pandangan atau pendapat narasumber mengenai topik tertentu dengan topik pertanyaan mengenai bagaimana interaksi parasosial ARMY terhadap BTS. Selain itu, peneliti juga mengamati kegiatan media sosial subjek penelitian terhadap idolanya.

Pada penelitian ini, narasumber ditentukan dengan kriteria tertentu. Kriteria narasumber penelitian ini adalah seorang ARMY (penggemar BTS), pernah menonton konser BTS di dalam negeri maupun di luar negeri, dan mengoleksi album atau merchandise BTS. Peneliti mengamati akun penggemar BTS di media sosial dan 
mengamati orang yang terkenal di fandom tersebut. Setelah menemukan orang-orang tersebut, peneliti menyaring kandidat narasumber sesuai kriteria yang sudah ditentukan.

Teknik analisis data yang digunakan dalam penelitian ini adalah teknik analisis data model interaktif. Menurut Miles dan Huberman, teknik analisis data model interaktif memiliki tahapan, yaitu pengumpulan data, reduksi data, display data dan kesimpulan (Herdiansyah, 2010). Peneliti menggunakan triangulasi sumber sebagai teknik keabsahan data pada penelitian ini.

\section{Hasil Temuan dan Diskusi}

Peneliti melakukan wawancara kepada enam orang informan. Hasil temuan dan diskusi ini akan peniliti paparkan menjadi beberapa sub-pembahasan, berikut dibawah ini:

\section{Narasumber Penelitian}

Narasumber pertama bernama Michelle. Michelle merupakan fangirl BTS berusia 21 tahun, berasal dari kota Jakarta dan saat ini sedang kuliah di Universitas Bina Nusantara. Michelle bercerita bahwa dirinya mulai tertarik dan mengikuti BTS sejak lagu 'Fire' yang dirilis pada 1 Mei 2016.

Narasumber kedua bernama Chintya. Chintya merupakan penggemar BTS perempuan yang saat ini berkuliah di Universitas Tarumanagara dan berusia 21 tahun. Chintya bercerita bahwa dirinya mengetahui BTS sejak mereka debut tahun 2013 tetapi baru masuk fandom sebagai ARMY pada tahun 2015.

Narasumber ketiga adalah Alphiandi, seorang fanboy BTS berusia 25 tahun dan bertempat tinggal di Depok. Saat ini Alphiandi mengelola channel Youtube pribadi dengan konten seputar K-Pop. Alphiandi menyukai BTS sejak melihat penampilan lagu I Need U melalui Youtube.

Narasumber selanjutnya merupakan penggemar perempuan bernama Tiffani Afifa. Tiffani berusia 28 tahun dan berasal dari Jakarta. Saat ini Tiffani juga aktif membuat konten seputar K-Pop di Youtube pribadinya. Tiffani bercerita bahwa ia sudah menjadi penggemar BTS sejak masa debut tahun 2013.

Narasumber kelima yang peneliti wawancarai adalah William Yuswan. William saat ini berusia 30 tahun, tinggal di Jakarta dan sudah menikah dan memiliki seorang anak. William menyukai BTS sejak mereka melakukan promosi lagu I Need U. Ia mengaku mulai tertarik setelah melihat teori-teori yang ada di MV BTS.

Narasumber terakhir bernama Kevin. Kevin merupakan fanboy BTS berusia 23 tahun dan berasal dari Jakarta. Kevin menyukai BTS sejak masa debut tahun 2013 karena melihat penampilan BTS lewat Youtube.

\section{Alasan Utama}

Stever menjelaskan bahwa terdapat tiga alasan utama yang membuat penggemar menyukai idolanya yaitu task attraction, identification attraction dan romantic attraction (Stever, 2013).

Alasan utama penggemar perempuan dan laki-laki menyukai BTS sama-sama karena bakat yang dimiliki oleh mereka dan juga ada ketertarikan untuk menjadi seperti mereka. Untuk alasan hubungan romantis, hal ini hanya terjadi terhadap fangirl. 


\section{Dimensi Interaksi Parasosial}

Seorang peneliti dari Belanda, Pekka (Setyanto, Winduwati dan Utami, 2017) menemukan lima dimensi yang menggambarkan interaksi parasosial yaitu pertemanan khayalan, mencari teman, empati kepada performer, realitas dari hubungan dan kompetensi performer.

Penggemar perempuan dan penggemar laki-laki sama-sama pernah memandang BTS sebagai teman atau saudara. Terjadi perbedaan antara fangirl dan fanboy di dimensi mencari teman, penggemar perempuan cenderung lebih aktif dalam fandom dan mencari teman sesama ARMY dibandingkan penggemar laki-laki yang hanya menyukai BTS tanpa terlalu aktif dan bersosialisasi dengan ARMY lainnya.

Dimensi interaksi parasosial selanjutnya adalah empati kepada performer, penggemar perempuan dan laki-laki sama-sama memiliki empati terhadap anggota BTS. Sebagai contoh saat anggota BTS mendapat ancaman dan hujatan, mereka juga ikut merasakan kekesalan dan sedih terhadap hal tersebut. Terjadi kesamaan lagi di usaha fangirl dan fanboy dalam usaha mereka menyaksikan BTS secara langsung dan membeli barang-barang tentang BTS.

\section{Efek Interaksi Parasosial}

Dalam interaksi parasosial memiliki efek-efek seperti sense of companionship, pseudo-friendship, pedoman dalam bertingkah laku, personal identity dan pemirsa patologis (Setyanto, Winduwati dan Utami, 2017).

Penggemar perempuan dan laki-laki mengalami efek yang tidak sama seperti contohnya penggemar perempuan menganggap BTS dapat mengurangi rasa sepi dan menjadi tempat berbagi cerita, sedangkan penggemar laki-laki tidak mengalami efek tersebut.

Efek interaksi parasosial selanjutnya juga hanya dialami oleh fangirl, rasa memiliki hubungan persahabatan dengan BTS ini tidak dialami oleh para fanboy. Fanboy cenderung melihat BTS sekedar sebagai idola mereka tidak berharap dapat menjalin hubungan yang lebih. Terdapat kesamaan lagi antara fangirl dan fanboy BTS, mereka sama-sama menjadikan BTS sebagai pedoman mereka bertingkah laku. Perilaku anggota BTS yang positif sebisa mungkin akan mereka tiru dan teladani.

Efek interaksi parasosial selanjutnya hanya dialami oleh penggemar perempuan. Fangirl menjadikan BTS sebagai sarana untuk memahami kehidupan mereka sendiri. Sedangkan penggemar laki-laki tidak terlalu memperhatikan perilaku apa yang BTS lakukan sehingga tidak dapat menjadikan BTS untuk memahami kehidupan masingmasing.

Di antara informan penelitian ini tidak ada yang sampai di efek patologis. Fangirl maupun fanboy sama-sama mengetahui batasan dan dapat menyortir tindakan yang baik untuk ditiru atau tidak. Mereka menjadikan BTS panutan di arah yang positif dan sebagai fans mereka berusaha untuk tidak meniru tindakan yang negatif.

Dapat dilihat dalam penelitan ini bahwa penggemar perempuan menyukai idola mereka dengan koneksi emosional sedangkan penggemar laki-laki dengan koneksi rasional. Fangirl lebih mengakui diri sebagai anggota fandom dan aktif dalam komunikasi maupun acara ARMY, sedangkan fanboy tidak tertarik untuk berkomunikasi dalam komunitas atau fandom. 


\section{Simpulan}

Permasalahan yang diteliti dalam penelitian ini adalah perbedaan interaksi parasosial fangirl dan fanboy ARMY Indonesia. Dengan mengumpulkan data, meneliti dan melihat sumber-sumber terdahulu, dalam penelitian ini terlihat bahwa interaksi parasosial fangirl dan fanboy memiliki persamaan dan perbedaan.

Kesamaan terlihat pada alasan fangirl dan fanboy menyukai grup BTS yaitu karena penampilan, bakat dan musik. Keduanya melihat BTS sebagai sosok panutan dan ingin menjadi seperti idolanya.

Hubungan fangirl dengan BTS kuat secara emosional sehingga respon fangirl terhadap segala sesuatu yang dilakukan BTS lebih impulsif. Di sisi lain, fanboy memaknai hubungannya dengan BTS secara rasional sehingga mereka mendukung namun memiliki batasan-batasan tertentu.

Hal tersebut terbukti dari ketertarikan menjalin hubungan yang lebih dengan idolanya, fangirl memiliki keinginan untuk menjadi sahabat, saudara bahkan pasangan anggota BTS. Sedangkan fanboy menganggap BTS sebagai idola mereka dan menyadari posisinya hanya sebagai penggemar dan pendukung.

Diantara kesamaan dan perbedaan interaksi parasosial yang dialami oleh fangirl dan fanboy, mereka menyadari batasan-batasan yang harus mereka jaga. Dalam menyukai dan mendukung BTS, keduanya memahami privasi dan kenyamanan idolanya. Fangirl dan fanboy juga siap membela dan mendukung saat serangan atau hal negatif menyerang BTS.

\section{Ucapan Terima Kasih}

Ucapan terima kasih penulis berikan kepada semua narasumber yang telah bersedia meluangkan waktu dan memberikan informasi kepada peneliti selama proses pengumpulan data penelitian ini. Peneliti juga ingin mengucapkan terima kasih kepada Fakultas Ilmu Komunikasi Universitas Tarumanagara. Terima kasih juga kepada keluarga, teman-teman dan segala pihak yang membantu penulis selama penulisan penelitian ini.

\section{Daftar Pustaka}

Abidin, Yunus. (2010). Strategi Membaca Teori dan Pembelajaranya. Bandung: Risqi Press.

Bungin, M. Burhan. (2009). Sosiologi Komunikasi: Teori, Paradigma, dan Diskursi Teknologi Komunikasi di Masyarakat. Jakarta: Kencana.

Herdiansyah, Haris. (2010). Metodologi Penelitian Kuantitatif. Jakarta: Salemba Humanika.

Kriyantono, Rachmat. (2012). Teknik Praktis Riset Komunikasi. Jakarta: Kencana Pernada Media Group.

Setyanto, Y., Winduwati, S., \& Utami, L. S. S.. (2017). Early Adolescent Behavior on Media Toward Idol Figure (Parasoial Study Preliminary Youth As An Effect of New Media). International Journal of Communication and Media Studies (IJCMS) Vol 7 Issue 2 May-Jun 2017. India: Transstellar Journal Publications \& Research Consultancy Pvt. Ltd.

Stever, Gayle S. (2013). Mediated vs. Parasocial Relationships: An Attachment Perspective. New York: Empire State College. 
(https://www.researchgate.net/publication/263258109_Mediated_vs_Parasocial _Relationships_An_Attachment_Perspective)

Sugiyono. (2009). Metode Penelitian Kuantitatif, Kualitatif dan R\&D. Bandung: Alfabeta.

Tambuarian, H.H. Daniel. (2018). Komunikasi Lintas Budaya Masyarakat Dayak Dalam Menjaga Kerukunan Hidup Umat Beragama. Jurnal Komunikasi Vol 10, No 1. 